\title{
Implantação do método activity based costing na logística interna de uma empresa química
}

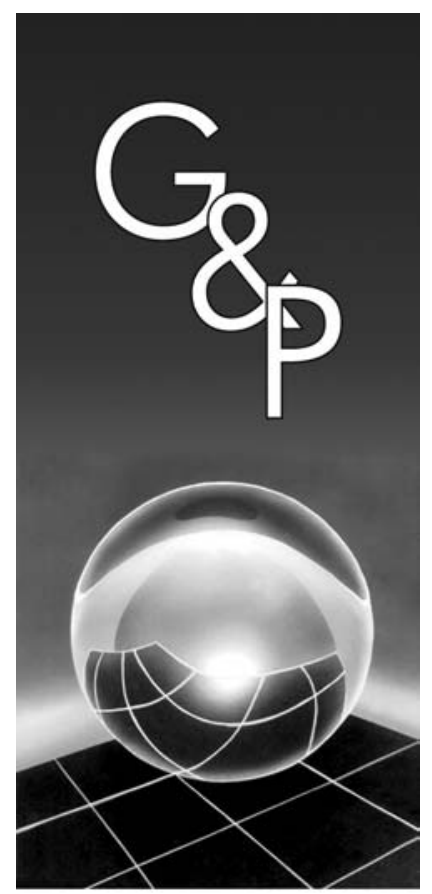

\author{
Themis Castro de Vasconcellos \\ Fernando Augusto Silva Marins \\ Jorge Muniz Junior
}

\section{Resumo}

Este trabalho tem como objetivo apresentar como o método ABC - activity based costing foi implantado para realizar o custeio da logística interna da empresa química BASF SA., situada na cidade de Guaratinguetá - SP. Apresentam-se: a descrição do processo de mudança do método de custeio tradicional para o método $A B C$, as dificuldades encontradas e como foram ultrapassadas, bem como as vantagens constatadas pela empresa. O departamento de logística da empresa funciona como um prestador de serviços, atendendo a todos os processos produtivos das divisões (unidades de negócio) existentes na planta de Guaratinguetá, no que concerne à armazenagem e ao fornecimento de matérias-primas, além de atuar na retirada e na armazenagem de produto acabado. Como principais resultados, obteve-se uma distribuição de custos mais justa entre as divisões da planta, identificação de oportunidades de melhoria nos processos logísticos, identificação de processo e atividades que não agregavam valor aos produtos, entre outros. Finalmente, o processo de implantação e os resultados foram muito bem avaliados pelos gestores, o que foi decisivo para a adoção do método ABC como sistema gerencial de custos logísticos da empresa.

Palavras-chave: Método ABC. Custeio. Logística interna. Indústria química. Estudo de caso.

\section{Introdução}

As mudanças ocorridas no ambiente de negócios brasileiros na década de 90 impuseram novos paradigmas para o gerenciamento empresarial. A abertura da economia, a sua estabilização e a presença cada vez mais marcante de negócios com abrangência global, exigiram a substituição do antigo modelo de gerenciamento empresarial, baseado na produtividade, por um novo modelo baseado na competitividade. Assim, o desenvolvimento de vantagem competitiva depende da capacidade da organização de se diferenciar dos concorrentes por meio da busca do equilíbrio entre os objetivos de prazo, qualidade, inovação e, principalmente, de custo.

Nesse novo cenário, a logística adquiriu uma dimensão estratégica no gerenciamento de uma organização, pois os serviços logísticos, bem estruturados, permitem a entrega de valores ao mercado. De fato, no horizonte econômico do país, há a necessidade das empresas trabalharem em cadeias que agreguem valores aos seus clientes. Borges (2003) afirma que a concorrência individual entre as organizações dará espaço à competição entre as cadeias logísticas nas quais as empresas estão inseridas.

À medida que as empresas vêm atuando em mercados cada vez mais competitivos, elas devem definir e aprimorar os seus processos logísticos, para obter um diferencial competitivo. Para isso, torna-se fundamental conhecer os custos relacionados a estes processos logísticos para buscar melhores soluções.

Uma dificuldade, observada na prática, consiste na carência de informações contábeis que sirvam para apoiar a correta tomada de decisões logísticas. Os sistemas de custeio convencionais oferecem os seus resultados orientados principalmente para os produtos, e a logística precisa de informações contábeis referentes às atividades (FARIA; COSTA, 2005). Uma opção que permite tais resultados é o custeio baseado nas atividades, ou método $\mathrm{ABC}$ - activity based costing (KAPLAN; COOPER, 2000), o qual além de permitir o custeio de produtos e serviços também é uma ferramenta útil na gestão de custos (MARTINS, 2003). 
É importante ressaltar que a área de logística de uma empresa é responsável por significativa parcela dos custos indiretos, os quais vêm apresentando participação crescente nos custos totais das empresas. Assim, para administrar a função logística, é de suma importância a análise do custo total; ou seja, para um dado nível de serviço oferecido ao cliente deve-se efetuar a minimização do custo logístico total, ao invés de minimizar o custo das atividades logísticas individualmente (FARIA; COSTA, 2005).

Um sistema de custos tradicional tem as finalidades de registro e análise dos resultados obtidos. Para que ele possa colaborar nas finalidades de planejamento, orçamento e controle, ou seja, para que ele possa ser um sistema de gestão de custos, é imprescindível acrescentar um método de custeio de produtos e serviços. Neste sentido, os métodos de custeio são subsistemas e também são escolhidos pela finalidade de uso; por exemplo, o método de custeio por absorção é utilizado para atender a finalidades fiscais; já o método de custeio variável/direto é utilizado para fins gerenciais e, finalmente, o método $\mathrm{ABC}$ é utilizado para empresas com alto grau de complexidade produtiva e com múltiplos produtos e clientes, ou seja, com custos indiretos e despesas operacionais expressivos (MAEHLER et al., 2006).

Como os custos da logística são predominantemente indiretos, verifica-se que os métodos tradicionais de custeio mostram-se inapropriados por não identificar claramente os custos logísticos e seus resultados financeiros. Assim, o método ABC surge como uma ferramenta adequada para a apuração de custos neste caso (COGAN, 2000).

Para agregar valor aos produtos, as melhorias em logística apresentam algumas contribuições, tais como: a redução no tempo de resposta ao cliente e serviços oferecidos junto às atividades básicas de distribuição, como forma de diferenciação. No entanto, como envolve várias funções administrativas e agentes da organização, o processo logístico pode ser desconhecido em sua totalidade, por haver sobreposição de responsabilidades. É importante entender a logística como um processo integrado entre as diversas funções, bem como os custos de cada atividade.

A logística tem por objetivo prover os clientes com produtos e serviços desejados, corretos, no lugar certo, no momento exato, na condição desejada e no menor tempo possível, o que pode ser alcançado por meio da administração adequada de três processos fundamentais: suprimentos, apoio à produção e distribuição física. Assim, faz-se necessário o desenvolvimento de instrumentos que possibilitem às empresas identificar e obter os custos logísticos para, em seguida, avaliá-los, auxiliando assim na tomada de decisões (FARIA; COSTA, 2005).
De fato, os problemas que afetam a rentabilidade de uma empresa se agravam quando há demora em percebê-los e quando há desconhecimento de suas causas. Desta forma, deve haver um esforço direcionado no sentido de identificar quais são os problemas, com o máximo de antecedência possível, e resolvê-los antes que se tornem mais críticos.

Isso fundamenta a importância dos sistemas gerenciais de custos em geral, e as razões que têm levado empresas a se interessar pela implantação do Método $\mathrm{ABC}$ nas operações logísticas, como um sistema gerencial de custos, estão relacionadas a seguir (LA LONDE; POHLEN, 1998 apud FREDERICO et al., 2006): possibilidade de se determinar os fatores que influenciam os custos logísticos; atribuição mais justa dos custos logísticos aos grupos de produtos; obtenção de dados de custos mais precisos; determinação de como a logística pode contribuir para a rentabilidade da empresa; identificação dos clientes, regiões ou canais de distribuição mais rentáveis e focalização dos esforços de melhoria nos processos que podem gerar benefícios (menores custos e maior qualidade, por exemplo) à empresa como um todo.

La Londe e Pohlen (1998) constataram também que, na opinião dos seus entrevistados, o Método $\mathrm{ABC}$ mostra bem o processo para custeio e mensura o desempenho do processo logístico, apresentando mais claramente a interligação crítica existente entre rentabilidade e os custos logísticos.

Neste contexto, este artigo descreve um modelo de custeio, baseado no método $\mathrm{ABC}$, para uma empresa do setor químico que permitiu apurar de forma mais consistente os custos logísticos e, ainda, identificar quais os principais processos envolvidos, a visualizar possíveis melhorias dos níveis de serviço, além de também ajudar na eliminação de atividades que não estavam agregando valor aos produtos e serviços.

Na sequiência do artigo, apresenta-se o delineamento e procedimento de pesquisa seguido pela revisão bibliográfica sobre os conceitos no processo logístico e sobre métodos de custeio, destacando-se os princípios do método ABC (activity based costing). Na quarta seção é feita a apresentação da BASF e descrito o método $\mathrm{ABC}$ para a logística interna, para atender às necessidades de custeio da empresa. Na quinta seção é feita a análise dos resultados obtidos com o novo modelo de custeio, apresentando-se as vantagens e desvantagens observadas. Nesta seção é feita uma comparação do método ABC implementado com o modelo de custeio tradicional (MTR) adotado até então pela empresa. As considerações finais e conclusões são apresentadas na última seção, bem como um resumo da visão dos gestores da empresa com relação ao novo método de custeio adotado. 


\section{Delineamento e procedimentos de pesquisa}

Este trabalho iniciou-se com o estudo de conceitos e métodos de custeio em variada literatura, incluindo livros, artigos de periódicos e eventos científicos, teses e dissertações, além de busca na Internet; na seqüência definiram-se as questões de ordem metodológica, como a observação e análise dos resultados, o que foi finalmente consolidado nas conclusões do trabalho. Como tem sido preconizado por vários autores (MARCONI; LAKATOS, 1999; GIL, 1994; SILVA; MENEZES, 2005), a metodologia científica caracteriza os caminhos e os meios utilizados para se realizar uma pesquisa, assim sendo, deve-se evidenciar claramente o método e a classificação da pesquisa - quanto à natureza, abordagem, objetivos e procedimentos técnicos adotados. Com respeito ao método aqui utilizado, pode-se dizer que o trabalho foi desenvolvido em cinco etapas.

a) estudo teórico sobre a gestão logística e métodos de custeio, particularmente sobre o método $\mathrm{ABC}$, como meio de obtenção de resultados consistentes. Aqui foram utilizados materiais bibliográficos para fornecer o embasamento teórico do trabalho;

b) apresentação de seminários aos gestores da BASF para familiarização destes com o método $\mathrm{ABC}$ e aprovação da validade do desenvolvimento do trabalho;

c) identificação dos principais processos logísticos, apuração dos custos destes processos;

d) aplicação do método ABC, para a apuração de custos junto ao departamento de logística interna, compreendendo todas as fases que eram desenvolvidas durante os processos de produção e distribuição de matérias-primas, produtos semi-acabados e acabados nas várias plantas da BASF em Guaratinguetá - SP, e comparação com a situação anterior quando se adotavam os métodos tradicionais de custeio; e

e) implantação do novo procedimento de custeio na BASF.

Com respeito à classificação da pesquisa, ela é de natureza aplicada, na medida em que buscou satisfazer uma necessidade presente na empresa considerada, desenvolvendo um sistema de custeio que permitiu identificar, consistentemente, os custos relativos a clientes e produtos, num cenário onde se observava crescente participação de custos indiretos e uma grande variedade de produtos e serviços oferecidos.

Quanto ao processo de abordagem, ela pode ser classificada como qualitativa, envolvendo uma mudança de procedimento da empresa no que concerne à apuração e alocação de seus custos logísticos. Quanto aos seus objetivos e procedimentos técnicos, pode-se dizer que se tratou de um trabalho de cunho teórico-empírico, pois se aplicou um método conhecido $(\mathrm{ABC})$ à realidade de uma empresa, e se caracterizou como um estudo de caso que, segundo Gil (1994), corresponde a um estudo aprofundado e exaustivo de um ou mais objetos, de maneira a propiciar um conhecimento mais amplo e detalhado. De fato, objetivou-se tratar o método $\mathrm{ABC}$ num contexto real (BASF), o que forneceu à pesquisa uma abordagem prática quanto a sua finalidade.

Várias são as razões que podem ser citadas para a adoção desta metodologia de pesquisa, como a possibilidade de busca de soluções para problemas reais a partir da aplicação de modelos teóricos e, ainda, permitir a fixação e validação dos conhecimentos teóricos adquiridos. Como delimitações do trabalho pode-se citar que foi adotado um agrupamento das atividades secundárias em grupos maiores, formando um conjunto de 7 macro-atividades (recebimento, estocagem, movimentação de entrega, movimentação de retirada, expedição operacional, administração da expedição e fluxo de embalagens); isso permitiu um bom ganho operacional relativo à implementação do novo método de custeio; também não foi incluída a logística de distribuição, por ser realizada em sua maior parte por empresas terceirizadas de transporte.

\section{Referencial teórico}

A área de atuação da Logística compreende desde o gerenciamento de materiais até a entrega do produto final ao local designado pelo cliente, sendo o elo entre o mercado e a atividade operacional. Neste cenário, segundo Borges (2003), as empresas procuram tornar suas cadeias logísticas mais ágeis e competitivas, agregando valor ao produto pela eliminação de atividades desnecessárias e implantando medidas de redução de custos.

Atualmente as empresas estão assumindo uma postura de cooperação para competir em conjunto, assim as cadeias logísticas objetivam construir processos logísticos integrados, que agreguem valor aos produtos e serviços. Elas estão compreendendo que a competição não mais ocorre entre uma companhia e outra, mas sim entre as cadeias logísticas nas quais as empresas estão inseridas (BALLOU, 2006). Uma das principais características da logística moderna é sua crescente complexidade operacional. Aumento da variedade de produtos, entregas mais frequientes, menores tempos de atendimento, menor tolerância a erros de separação de pedidos e pressões para redução dos níveis de estoque são alguns dos principais indicadores dessa complexidade. Uma das conseqüências deste fenômeno é que alguns componentes do custo logístico, até então pouco significativos, como, por exemplo, os custos de armazenagem, passaram a ter uma participação importante. 
Tudo isto tem levado as empresas em direção a um contínuo processo de modernização, tanto tecnológica, quanto gerencial. É importante saber como estão sendo alocados esses custos, que no passado eram pouco relevantes e que vêm se tornando cada dia mais importantes. A incapacidade de responder a esta pergunta pode gerar nas empresas um sério problema de credibilidade das informações contábeis, com reflexos negativos sobre a qualidade do processo decisório. Além disso, num mercado cada vez mais globalizado, a concorrência passa a ter escala mundial, o que favorece a escolha por bens e serviços de alta qualidade a baixos custos. A meta passa a ser a eficiência, e com isso as informações de custos passam a ser cada vez mais relevantes.

Por outro lado, e decorrente dos aspectos citados, a logística tornou-se um assunto vital por absorver parte significativa do orçamento operacional da empresa, pois envolve importantes atividades de planejamento, organização e controle no que concerne a: transporte, gestão de estoques, processamento de pedidos, compras, movimentação, armazenagem, manuseio de materiais, embalagem e programação da produção. Assim, os sistemas de custos tradicionais já não são mais eficazes para os gerentes tomarem decisões logísticas, por apresentar informações estáticas, que se prestam mais às análises financeiras do que às decisões estratégicas das empresas.

A necessidade de uma ligação entre as atividades e os custos tem importância crucial para tornar a contabilidade gerencial de grande valor para os gerentes de hoje e, no entanto, a alocação mais precisa e confiável tem como contrapartida uma maior sofisticação e complexidade contábil. Isso sinaliza a necessidade de ser criterioso no momento de decidir sobre o nível de detalhamento e sofisticação do sistema de custeio.

Como as atividades ligadas à Logística são complexas e interligadas, há uma dificuldade na apuração dos custos relativos a estas atividades, que são essencialmente realizadas a partir de uma estrutura de apoio e, assim, representam custos indiretos, dificultando a identificação dos custos de cada atividade isoladamente.

\subsection{Métodos de custeio}

Há pelo menos três maneiras de se atribuir valor à produção de bens e serviços, ou seja, como fazer o custeio destes produtos e serviços: custeio por absorção (LEONE, 1997; GARRISON; NOREEN, 2001), custeio variável (MARTINS, 2003; CREPALDI, 1999) e o método ABC (MARTINS, 2003; KAPLAN; COOPER, 2000), também conhecido por custeio baseado na atividade. Os dois primeiros métodos são os que são adotados tradicionalmente nas empresas em geral. As duas primeiras maneiras de atribuição de valor são as formas tradicionais de custeio, que têm se mostrado inapropriadas para empresas que atuam em mercados instáveis ou que fornecem produtos inovadores e bastante diversificados, em que os custos dos recursos são relevantes e de difícil apuração. Empresas com estas características precisam de um sistema de custeio mais adequado às suas necessidades e neste sentido, o método $\mathrm{ABC}$ é uma opção. $\mathrm{O}$ Quadro 1 apresenta algumas deficiências dos modelos de custeio tradicional.

$\mathrm{O}$ método $\mathrm{ABC}$ nasceu nos Estados Unidos com a publicação do artigo Measure costs right: make the right decision (COOPER; KAPLAN, 1988). A idéia básica deste procedimento é identificar os principais processos e atividades dentro de uma empresa, apurar os custos destas atividades, entendendo seu comportamento e, então, chegar aos custos dos produtos e serviços resultantes destes processos (BORNIA, 2002). Este sistema de custeio surgiu para reduzir as distorções causadas pela arbitrariedade do rateio dos custos indiretos de fabricação. Antes esta arbitrariedade era aceita, pois a proporção dos custos indiretos de fabricação em comparação aos demais custos era pequena, hoje com o advento da tecnologia e a crescente implantação de sistemas como o just-in-time (JIT), computer integrated manufacturing (CIM), entre outros, os custos indiretos de fabricação foram crescendo, aumentando assim as distorções provocadas pela arbitrariedade no critério de rateio (COGAN, 2000).

De acordo com Blocher et al. (2007), um custo direto pode ser facilmente atribuído para um grupo ou objeto de custo. Por exemplo, o custo dos materiais utilizados na fabricação de um produto pode ser diretamente identificado com o produto fabricado. Entretanto, isso não ocorre na identificação do impacto de um custo indireto num objeto de custo. O custo de supervisionar trabalhadores, manusear materiais, custos de instalações, uso de equipamentos de apoio como empilhadeiras são exemplos de custos indiretos que serão tratados no decorrer do trabalho.

Como observado por Novaes (2001), logo após o término da $2^{\text {a }}$ Guerra Mundial os custos indiretos representavam apenas $10 \%$ do custo total, sendo que hoje esse valor pode chegar até $50 \%$ dos custos de um produto ou

Quadro 1. Deficiências dos modelos de custeio tradicionais.

\begin{tabular}{ll}
\hline \multicolumn{1}{c}{ Principais falhas } & \multicolumn{1}{c}{ Conseqüências } \\
\hline $\begin{array}{l}\text { Não permitem o controle de } \\
\text { todos os recursos necessários } \\
\text { às atividades. }\end{array}$ & $\begin{array}{l}\text { Não permitem a identificação } \\
\text { de atividades que não agregam } \\
\text { valor. }\end{array}$ \\
$\begin{array}{l}\text { Utilizam apenas valores de } \\
\text { custos baseados em volumes. }\end{array}$ & $\begin{array}{l}\text { Transmitem informações } \\
\text { imprecisas de custos para os } \\
\text { administradores. }\end{array}$ \\
$\begin{array}{l}\text { Apropriação dos custos fixos/ } \\
\text { indiretos torna-se injusta } \\
\text { (múltiplos produtos, diversida- } \\
\text { de de produtos e diversidade a apuração das } \\
\text { de volume). }\end{array}$ & $\begin{array}{l}\text { margens de contribuição de } \\
\text { produtoduto ou de linhas de }\end{array}$ \\
\hline
\end{tabular}


serviço. Ainda com respeito a isso, segundo Padoveze (1997), “o grande problema da alocação de custos está nos custos indiretos. Normalmente tidos como fixos, em relação ao volume de produção, são alocados aos diversos produtos por critérios de distribuição, também chamados de rateios. Entende-se que esses critérios são arbitrários ou subjetivos; por isso, invalidam o correto custeamento dos produtos".

Padoveze (1997) ainda afirma que "os procedimentos de aplicação dos custos fixos indiretos de produção aos produtos através de percentuais de absorção, baseados em alguma medida razoável de atividade, tais como horas-máquinas e fabricação, horas ou valor de mão-deobra direta, têm produzido enormes erros na atribuição de consumo de recursos dos departamentos indiretos para os produtos individuais, provocando também sérias distorções na formação de preços de venda baseados nos custos de fabricação".

$\mathrm{O}$ método $\mathrm{ABC}$, conforme é apresentado aqui, tem como base conceitual o entendimento de que as atividades consomem recursos, e os produtos por sua vez, demandam atividades. A diferença com os sistemas tradicionais de custeio está no fato de que esses consideram que os custos são provocados pelo volume medido, usualmente, pelo número de itens produzidos, horas de mão-de-obra, horas-máquinas, entre outros similares. Já o custeio baseado em atividades parte do princípio que as atividades geram os custos e que através do controle das atividades a empresa conseguirá gerenciar os custos de produção. Portanto, a partir do momento que se identificam as atividades e os seus direcionadores de custos, torna-se possível entender o comportamento dos custos, e quais acrescentam ou não valor ao produto.

\subsection{Método de custeio ABC}

O custeio baseado em atividades é, freqüentemente, apresentado de forma bastante diversificada. Isso porque a principal diferença entre esse sistema e os outros tradicionais não está relacionada ao método de cálculo e sim ao princípio. Ele busca identificar quais são as principais informações que as empresas necessitam e para que serão utilizadas. Assim, seu interesse está na forma como serão utilizadas as informações obtidas, objetivando a melhoria dos processos e a redução de desperdícios. Vê-se, portanto, que seu enfoque vai além de ser apenas um sistema de custo, mas como tem um enfoque gerencial, passa a ser um sistema de gestão de custos.

Nesse contexto surgiu a idéia de se utilizar o termo gerenciamento baseado em atividades (ABM - activity based management), para caracterizar essa nova abordagem gerencial dos custos (BORNIA, 2002). De fato, como apontado por Novaes (2001), o método ABC já tem duas gerações, conforme exposto no Quadro 2. Assim, nessa $2^{\text {a }}$ geração do método $\mathrm{ABC}$, um outro aspecto
Quadro 2. Gerações do método ABC (NOVAES, 2001).

\begin{tabular}{lll}
\hline \multicolumn{1}{c}{$\begin{array}{c}\mathbf{1}^{\text {a }} \text { Geração do } \\
\text { método ABC }\end{array}$} & \multicolumn{1}{c}{\begin{tabular}{c}
\multicolumn{1}{c}{$\mathbf{2}^{\text {a }}$ Geração do } \\
método ABC
\end{tabular}} \\
\hline Foco & $\begin{array}{l}\text { Problema de apropria- } \\
\text { ção de custos dentro dos } \\
\text { departamentos em que a } \\
\text { empresa tradicionalmente } \\
\text { é dividida. }\end{array}$ & $\begin{array}{l}\text { Denominada de ABM } \\
\text { (activity based manage- } \\
\text { ment) enfoca a íntegra do } \\
\text { processo operacional. }\end{array}$ \\
Objetivo & $\begin{array}{l}\text { Interligar os custos } \\
\text { diversos de um departa- } \\
\text { mento da empresa com os os } \\
\text { objetos de custeio, sem, } \\
\text { contudo, quebrar os limi- } \\
\text { tes interdepartamentais } \\
\text { clássicos. }\end{array}$ & $\begin{array}{l}\text { Rastrear os desdobramen- } \\
\text { tos de um serviço especí- } \\
\text { fico voltado a um cliente } \\
\text { externo, desde a entrada } \\
\text { do pedido, até a satisfa- } \\
\text { ção final do consumidor/ } \\
\text { cliente. }\end{array}$ \\
\hline
\end{tabular}

conceitual que chama a atenção é que essa técnica de custeio se propõe a acompanhar, e não só alocar, a utilização de recursos aos produtos ou serviços, procurando estabelecer uma relação direta entre os recursos e produtos ou serviços, o que conseqüentemente possibilita uma identificação da relação de causa/efeito bastante transparente.

Portanto, o referido sistema, procura tratar todos os custos como se fossem custos diretos, até pelo entendimento de que todos os custos são indispensáveis à produção de um determinado item. Caso contrário, não se justificaria a existência de determinados custos, que somente onerariam os fatores de produção. $\mathrm{O}$ método visa à atribuição mais rigorosa de gastos indiretos ao bem ou ao serviço produzido na empresa, permitindo um controle mais efetivo desses gastos e oferecendo melhor suporte às decisões gerenciais.

É importante ressaltar que a implementação do novo método de custeio exige uma visão holística da gestão, na qual a empresa seja vista e compreendida em seu todo, havendo a necessidade de se trabalhar aos moldes da gestão participativa, em que todas as pessoas que atuam direta ou indiretamente junto ao processo produtivo estejam envolvidas nesse sistema de gerenciamento de custos. Pode-se dizer que se trata de uma técnica de contabilidade analítica que mede o custo das atividades de uma empresa, atribuindo este custo ao produto ou serviço, ou ainda a outros objetos de custo, ou seja, elementos para os quais convêm conhecer o custo.

Assim, o método ABC (Figura 1) baseia-se na constatação de que são as atividades que desencadeiam o consumo de recursos; os quais, por sua vez, estão identificados com custos (mão-de-obra, materiais, mercadorias, por exemplo) na contabilidade da empresa. As atividades são as ações (manufatura do produto A, disponibilização do serviço B, comercialização e marketing, por exemplo) que a empresa adota para fornecer os seus produtos ou serviços aos clientes. Assim, para cada produto final, pode-se avaliar qual foi o seu custo, nas várias fases da 


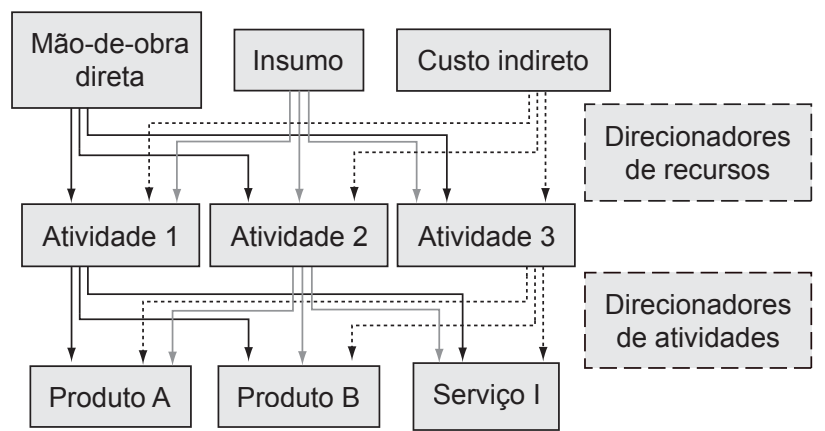

Figura 1. Ilustração do método $\mathrm{ABC}$ (Adaptado: SABADIN et al., 2006).

sua produção. Este método é útil para estabelecer preços no mercado e também para identificar as oportunidades.

$\mathrm{O}$ método $\mathrm{ABC}$ demonstra a relação entre recursos consumidos, atividades executadas e objetos de custeio, conforme ilustrado no Quadro 3 e está exemplificado na Figura 1. De fato, o fator principal para o sucesso do método $\mathrm{ABC}$ é a correta definição dos direcionadores de custos. Esses direcionadores, segundo Martins (2003), podem ser:

a) direcionadores de recursos (cost drivers) - determinam a ocorrência de uma atividade; $\mathrm{e}$

b) direcionadores de atividades (activity drivers) identificam como os produtos/serviços consomem as atividades.

Um ponto importante a se destacar é a necessidade de que os direcionadores consigam captar as relações de causa e efeito dos custos, pois através delas é que serão guiados os esforços de redução e controle dos custos, visando à realização de uma gestão consistente.

$\mathrm{O}$ método $\mathrm{ABC}$, através da sistemática de apropriação dos custos às atividades, mediante o uso dos direcionadores de recursos, e dos custos das atividades aos produtos por meio dos direcionadores de atividades, procura reduzir os efeitos prejudiciais de rateios arbitrários comuns nos sistemas tradicionais, proporcionando cálculos de custos mais acurados tanto para as atividades quanto para os produtos, e implementando uma gestão adequada dos custos.

\section{Implantação do método ABC numa empresa química}

A empresa analisada na aplicação do modelo de custeio proposto é uma empresa do setor químico, localizada na região do Vale do Paraíba, na cidade de Guaratinguetá, Estado de São Paulo. A BASF S.A. é uma empresa química, de origem alemã, com sede em Ludwigshafen e foi fundada em 1865. Ela está presente em todos os países da América do Sul, com exceção das Guianas e Suriname e suas unidades de produção, distribuídas em
Quadro 3. Lógica do método ABC (SABADIN et al., 2006*).

\begin{tabular}{ll}
\hline \multicolumn{1}{c}{ Item } & \multicolumn{1}{c}{ Explicação (exemplos) } \\
\hline Recursos & O que foi gasto (água, luz ou salários) \\
Atividades & $\begin{array}{l}\text { Onde foi gasto (manutenção, recursos humanos } \\
\text { ou vendas) }\end{array}$ \\
$\begin{array}{l}\text { Objetos de } \\
\text { custeio }\end{array}$ & \\
\hline
\end{tabular}

*Adaptado

39 países, conduzem negócios com clientes em mais de 170 nações.

As vendas são realizadas diretamente aos clientes sem intermediários. A logística de distribuição da BASF é feita por empresas de transporte terceirizadas, que utilizam os modais rodoviário e ferroviário.

A logística interna da empresa, que não é terceirizada, funciona como uma prestadora de serviços às áreas produtivas da empresa, atendendo todas as unidades produtivas da planta de Guaratinguetá, na armazenagem e fornecimento de matérias-primas para as produções e retirada, armazenagem e expedição de produto acabado. São seis depósitos para armazenagem de produtos, divididos entre matéria-prima e produto acabado.

Os principais objetivos da implantação de um sistema de gerenciamento de custos com base nas atividades desenvolvidas pela área de logística da BASF estão relacionados com a facilidade e a precisão que a administração terá para apurar e controlar seus custos reais de produção e, principalmente, os custos indiretos comuns (aqui chamados de overhead); identificar e mensurar os custos da não qualidade (falhas internas e externas, prevenção, avaliação, entre outros); levantar informações sobre as oportunidades para eliminar desperdícios e aperfeiçoar atividades; eliminar/reduzir atividades que não agregam valor ao produto para o cliente; identificar os produtos e clientes mais lucrativos; subsidiar o redimensionamento da plataforma de vendas (distribuidores e revendedores); melhorar substancialmente sua base de informações para tomada de decisões; e estabelecer um conjunto de indicadores de desempenho capaz de medir a eficiência e a eficácia da empresa sob aspectos produtivo, comercial, financeiro e societário.

Em resumo, na etapa da implantação do método $\mathrm{ABC}$ na área da logística interna da empresa, foram feitas as identificações:

a) dos recursos utilizados na empresa;

b) dos principais processos e das atividades realizadas a partir dos recursos;

c) dos direcionadores de recursos e atividades. Essa etapa foi importante, pois criou a oportunidade de se fazer uma análise crítica das atividades e uma possível realocação dos recursos entre elas, buscando a contínua melhoria dos processos; e 
d) das relações entre os objetos de custos (clientes, produtos ou serviços oferecidos) e os processos e atividades mapeadas.

\section{Detalhamento das etapas de implementação do método $A B C$}

A etapa de implementação do método consistiu na análise da empresa, sendo que nesta fase foi investigada a organização, conhecendo-se a filosofia de trabalho adotada, a forma como a empresa abordava o cliente, as instalações utilizadas, os produtos e serviços oferecidos e os principais processos nas áreas envolvidas.

Para investigar quais eram as atividades realizadas no processo de logística, partiu-se do recebimento de matéria-prima. Para efeito de simplificação algumas atividades básicas foram agrupadas conforme o fluxo logístico da Figura 2, que apresenta as 7 atividades principais.

Numa visão macro, a logística é responsável pelo recebimento da matéria-prima (atividade 1) e sua armazenagem até o momento de utilização pela produção (atividade 2). Assim que a produção solicita o material, cabe à logística entregar o material certo, no local certo e no momento certo (atividade 3). Para que então os materiais sejam transformados e seja obtido o produto acabado desejado, que deverá ser retirado da produção e armazenado (atividade 4), para que então o produto seja efetivamente expedido (atividade 5) a partir da realização da venda do mesmo (atividade 6). Em paralelo, a Logística deve atender toda a demanda de embalagem necessária (atividade 7).

Para a preparação do ambiente, primeiramente realizou-se uma reunião com todas as pessoas envolvidas no processo de logística interna da empresa, quando foi então apresentado o método $\mathrm{ABC}$, proposto como uma alterna-

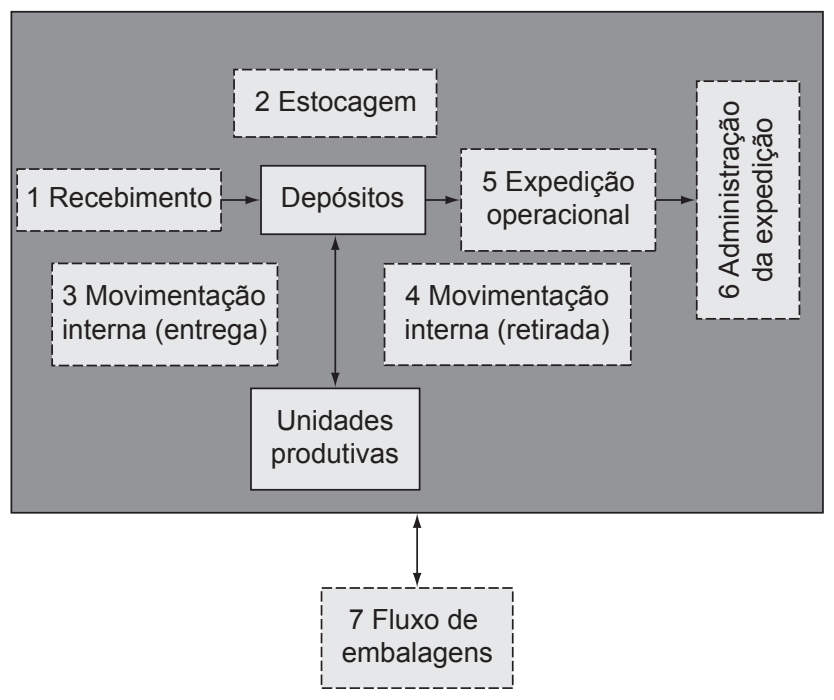

Figura 2. Principais atividades logísticas na BASF. tiva para a apuração dos custos por clientes internos, no caso, as plantas produtivas que a Logística atendia dentro da empresa em Guaratinguetá.

Foi ressaltada a importância do método como uma visão inovadora e ainda foram expostas as etapas a serem cumpridas, ressaltando a relevância quanto ao envolvimento e comprometimento de todos, para que fosse permitida a identificação de oportunidades de melhorias com melhor utilização de recursos.

Como a fábrica adotava o método de centro de custos, foi possível apurar as despesas mensais relacionadas à logística interna da empresa. As principais despesas eram com salários, insalubridade, periculosidade, indenizações, participação nos resultados, impostos em geral, depreciações, serviços de manutenção e combustível. Conforme sua classificação, foi feita a alocação dos recursos às atividades, conforme exposto no Quadro 4. Desta forma, após uma discussão com os gerentes da área, os custos dos recursos foram classificados em seis categorias gerais, sendo elas: estrutura, overhead (aqui entendido como custo indireto na prestação dos serviços logísticos), equipamento, pessoal, informática (uso do sistema ERP - SAP) e informática (uso de PC's).

Para as despesas de pessoal, o direcionador escolhido foi a porcentagem do tempo de cada colaborador gasto em cada atividade, o que se justifica uma vez que as principais despesas são relativas a encargos, salários, seguros, assistências e impostos. Assim, as atividades que consomem mais tempo dos colaboradores devem ser responsáveis pelas maiores despesas. Foi feita uma listagem de todos os colaboradores envolvidos e uma média do tempo gasto por eles em cada atividade.

Para as despesas de equipamentos, o direcionador escolhido foi a porcentagem de tempo gasto nos turnos com cada atividade. Este critério é bastante razoável, uma vez que as principais despesas são relativas ao combustível, à depreciação e à manutenção, ou seja,

Quadro 4. Direcionadores de recursos.

\begin{tabular}{ll}
\hline \multicolumn{1}{c}{ Atividades } & \multicolumn{1}{c}{ Direcionador de recursos } \\
\hline Pessoal & $\begin{array}{l}\text { Tempo dedicado a cada atividade. } \\
\text { Tempo que cada equipamento é } \\
\text { utilizado nas atividades. } \\
\text { Tempo que cada colaborador } \\
\text { utiliza o SAP para cada atividade. }\end{array}$ \\
Tempormática - SAP & $\begin{array}{l}\text { Tempo que cada colaborador } \\
\text { utiliza o computador para cada } \\
\text { atividade. }\end{array}$ \\
& $\begin{array}{l}100 \% \text { da alocação para a ativida- } \\
\text { de de estocagem. }\end{array}$ \\
Infra-estrutura & $\begin{array}{l}\text { Iguais porcentagens para as } \\
\text { atividades. }\end{array}$ \\
Overhead & $\begin{array}{l}100 \% \text { da alocação para a ativida- } \\
\text { de 'Administração da expedição'. }\end{array}$ \\
Administração da expedição
\end{tabular}


quanto maior o tempo de uso, maior a despesa com os equipamentos. Para tanto foram listados todos os equipamentos e foram apurados os tempos em que cada um era utilizado durante a realização de cada atividade nos dois turnos que a fábrica trabalha.

Para as despesas com informática relacionadas ao uso do ERP, foi feita uma relação dos colaboradores que possuem licenças da SAP para o uso do software e foi colhido o tempo que cada colaborador gastava no ERP com cada atividade, assim o direcionador escolhido foi a porcentagem de licença-hora utilizada em cada atividade, justificado pelo fato de que as maiores despesas eram com o serviço de licença da SAP, com a consultoria da SAP e outros serviços ainda relacionados ao ERP.

Para as despesas com informática relacionadas a PC's, foram listados todos os equipamentos deste tipo e o direcionador escolhido foi a porcentagem de computador-hora utilizada em cada atividade, o que é justificado pelo fato das principais despesas serem com manutenção de informática, serviços de informática, serviços aos clientes, help desk, administração de dados e informações.

No caso das despesas com infra-estrutura verificou-se que $100 \%$ das despesas se referiam apenas à atividade de estocagem, assim, como direcionador foi considerada a porcentagem de área utilizada por cada depósito e todos os custos de infra-estrutura foram alocados $100 \%$ para a atividade de estocagem.

Para as despesas que foram chamadas de overhead, pôde-se observar que eram custos que deveriam ser igualmente distribuídos entre as atividades, como consumo de material de limpeza e higiene, consumo de material de escritório, treinamentos, telefones, despesas com viagens, entre outros, por se tratarem de custos indiretos relacionados à prestação de serviços. No caso da atividade 'Administração da expedição', existia um centro de custo, onde eram identificadas todas as contas referentes a essa atividade, assim, o valor total deste centro de custo foi inteiramente alocado para essa atividade. Isso está ilustrado no Quadro 4.

Estabelecidos os direcionadores de recursos e após a alocação dos recursos às atividades, partiu-se para a determinação dos direcionadores de atividades, para que fosse feita, então, a alocação das atividades aos objetos de custeio. Conforme já mencionado, a logística da BASF atende aos seus clientes internos, ou seja, as plantas produtivas da empresa. Cada planta é dividida em unidades de negócio de vendas (SBU’s - sales business units), e as despesas por centro de custo são rateadas para as SBU's que demandam serviços logísticos, assim, desta forma, estas últimas são os objetos de custeio.

Iniciou-se, então, a definição dos direcionadores de atividades a serem utilizados, sempre tendo como objetivo a busca de direcionadores de fácil obtenção e manutenção. Utilizando-se o banco de dados disponível na empresa, denominado Data Warehouse (DW), foram identificados os principais direcionadores a serem adotados para atribuir os gastos com as atividades aos principais objetos de custos. O DW é uma ferramenta utilizada na empresa, que busca informações no ERP e as compila para a forma que o usuário necessita, assim várias informações podem ser obtidas a respeito de todas as movimentações que são registradas no ERP. Os direcionadores de atividades selecionados estão no Quadro 5.

No caso da escolha do direcionador da atividade de estocagem, observou-se que somente a quantidade de toneladas armazenadas não faria com que a divisão fosse justa, já que grande parte do custo estava associada aos dias em que os produtos se encontravam armazenados. Surgiu, então, uma dificuldade na identificação desse tempo de permanência em estoque para que pudesse ser feita a determinação da porcentagem de rateio dessa atividade.

Infelizmente, não foi possível obter informações diretamente pelo DW, pois este não fornecia o número médio de dias que cada unidade de negócio (SBU’s) mantém seus produtos estocados (giro de estoque), assim essa informação teve que ser estimada através do plano anual (PA), que é feito todo início de ano. É válido ressaltar que pode haver divergências entre o giro de estoque que é estabelecido no PA e o tempo real de armazenagem dos produtos, no entanto, no momento em que este trabalho foi realizado, a BASF não contava com uma ferramenta que fornecesse esses dados de uma forma confiável.

Uma particularidade foi observada na escolha do direcionador da atividade 'administração da expedição'. Pelo DW foi possível obter informações apenas das notas fiscais (NF) que eram emitidas pelo sistema. Como essas NF identificavam os produtos e seus respectivos códigos, gerando baixa no estoque, isso possibilitou a identificação da SBU responsável pela transação. No entanto, existiam NF que precisavam ser preenchidas manualmente como, por exemplo, as notas de serviço, notas de industrialização, notas de sucata, notas de resíduo, entre

Quadro 5. Direcionadores de atividades.

\begin{tabular}{|c|c|}
\hline Atividades & Direcionador de atividades \\
\hline Recebimento & Páletes recebidos no período por SBU. \\
\hline Estocagem & $\begin{array}{l}\text { Média de páletes armazenados nos me- } \\
\text { ses em análise, ponderados pelo tempo } \\
\text { de armazenagem por SBU (último dia } \\
\text { do mês). }\end{array}$ \\
\hline Mov. interna - entrega & Páletes entregues no período por SBU. \\
\hline Mov. interna - retirada & Páletes retirados no período por SBU. \\
\hline Expedição & Páletes expedidos no período por SBU. \\
\hline Fluxo de embalagens & $\begin{array}{l}\text { Páletes de embalagens recebidos e } \\
\text { entregues no período, ponderados pela } \\
\text { complexidade do tipo de embalagem, } \\
\text { por SBU. }\end{array}$ \\
\hline
\end{tabular}


outras, que não estavam associadas diretamente a um produto/código. Desta maneira as informações referentes a essas notas deveriam ser obtidas através do relatório de NF emitidas por SBU, o que é era feito mensalmente na empresa.

Outra ressalva a ser feita é sobre a determinação da porcentagem de rateio para a atividade de recebimento. Deveriam ser considerados todos os estornos ocorridos no período, ou seja, deveriam ser somadas as quantidades em toneladas recebidas de matéria-prima e produtos acabados para revenda (que poderiam vir de outras unidades da BASF para completar uma venda) e desse valor subtrair a soma em toneladas de estornos que foram realizados.

Assim, os direcionadores de atividades foram adotados a partir da identificação da relação causa e efeito estabelecida entre as diversas atividades e os objetos de custeio. É importante ressaltar que os direcionadores de custos (recursos e atividades) deveriam ser de fácil utilização para se evitar a criação de um modelo oneroso e complexo.

\section{Análise dos resultados}

Apresentam-se no Quadro 6 os resultados comparativos entre os percentuais das despesas dos centros de custos alocados para cada uma das unidades de negócios (SBU) nos anos de 2005, usando o método tradicional de rateio (MTR), e em 2006, usando tanto o MTR como o método ABC. As SBU foram as divisões de agroindústria, tintas, dispersões plásticas, plásticos e outras (corantes e pigmentos e produtos intermediários), e os centros de custos foram depósito, movimentação e administração de expedição.

No Quadro 6 (valores em negrito) ficou evidenciado que pelo MTR não se considerava a queda de produção da SBU Agronegócio que ocorre sempre nos primeiros semestres de cada ano. De fato, essa SBU tem seu pico de vendas no segundo semestre de cada ano, alavancado pelo aumento de demanda da agricultura nacional neste semestre. Pelo plano anual (MTR), essa sazonalidade era desconsiderada, e a porcentagem de rateio da SBU Agronegócios era maior que as porcentagens das outras unidades de negócio e, por esse motivo, ela era onerada com a maior parte dos custos logísticos.

Com o método ABC passou-se, agora, a considerar essa sazonalidade de produção e venda e, conseqüentemente, os valores das despesas alocadas à SBU agronegócio, oriundos dos centros de custo depósito e movimentação de materiais, foram menores com relação àquele preconizado pelo MTR, refletindo a queda de produtividade dessa SBU no $2^{\circ}$ semestre.

Já a segunda maior SBU, a Divisão de Tinta, manteve sua produção praticamente constante ao longo dos anos e, por isso, sua taxa de rateio se apresentou mais alta pelo método $\mathrm{ABC}$ do que pelo MTR. O novo método se mostrou mais justo, visto que essa SBU teve, de fato, um patamar de produção maior que o das demais áreas, e assim foi a área que mais utilizou os serviços logísticos nos períodos em análise.

Com relação aos centros de custo de depósito e movimentação, nota-se que a divisão de plásticos, por exemplo, que em 2006 não receberia nenhuma despesa pelo MTR passou a receber com o método $\mathrm{ABC}$, pois na realidade utilizavam os serviços logísticos, mesmo que numa proporção menor que as demais áreas.

Desta forma, o método ABC tornou a distribuição das despesas mais justa com relação à utilização dos serviços logísticos. Vê-se, portanto, que a empresa tomaria decisões inadequadas sem o método $\mathrm{ABC}$, e desta maneira estaria aumentando artificialmente o custo de alguma divisão em detrimento de outras.

Seguem alguns detalhes adicionais sobre a implantação do método ABC na BASF:

a) no plano anual era estabelecido um percentual fixo de alocação de despesas em função de volumes de produção planejados pelas SBU. O método ABC

Quadro 6. Comparação do método ABC e o método tradicional de rateio.

\begin{tabular}{|c|c|c|c|c|c|c|c|}
\hline & & \multicolumn{6}{|c|}{ Unidade de negócio (UBS) } \\
\hline & & $\begin{array}{c}\text { Agroindústria } \\
(\%)\end{array}$ & $\begin{array}{c}\text { Tintas } \\
(\%) \\
\end{array}$ & $\begin{array}{c}\text { Dispersões plásticas } \\
(\%)\end{array}$ & $\begin{array}{c}\text { Plásticos } \\
(\%) \\
\end{array}$ & $\begin{array}{c}\text { Outras } \\
(\%)\end{array}$ & $\begin{array}{c}\text { Total } \\
(\%)\end{array}$ \\
\hline \multirow[t]{3}{*}{ Depósito } & MTR - 2005 & 47 & 30 & 23 & 0 & 0 & 100 \\
\hline & MTR - 2006 & 49 & 31 & 21 & 0 & 0 & 100 \\
\hline & ABC - 2006 & 27 & 48 & 22 & 2 & 2 & 100 \\
\hline \multirow[t]{3}{*}{ Movimentação } & MTR - 2005 & 35 & 43 & 18 & 1 & 3 & 100 \\
\hline & MTR - 2006 & 43 & 40 & 16 & 0 & 2 & 100 \\
\hline & $\mathrm{ABC}-2006$ & 32 & 44 & 19 & 2 & 3 & 100 \\
\hline \multirow[t]{3}{*}{ Administração de expedição } & MTR - 2005 & 29 & 38 & 25 & 5 & 3 & 100 \\
\hline & MTR - 2006 & 33 & 36 & 24 & 6 & 2 & 100 \\
\hline & $\mathrm{ABC}-2006$ & 33 & 31 & 21 & 8 & 7 & 100 \\
\hline
\end{tabular}


definiu uma porcentagem variável mensal como função das quantidades reais movimentadas e notas fiscais emitidas;

b) como os relatórios do DW forneciam as quantidades produzidas em quilos, foi feita a conversão para número de páletes utilizados no transporte dessas quantidades usando uma tabela de conversão consensual por SBU;

c) o período considerado na aplicação do método ABC foi do dia 21 do mês anterior ao dia 20 do mês corrente. Isso para que os dados fossem apurados mensalmente e repassados à contabilidade da empresa para que as SBU fossem informadas em tempo hábil para eventuais contestações e refinamento; e

d) trimestralmente se fez uma revisão e atualização das bases de dados utilizadas na determinação dos direcionadores de recursos.

Com o método $\mathrm{ABC}$, puderam ser observadas algumas vantagens. Uma das mais relevantes é a visão geral de todo o processo logístico desenvolvido na fábrica, o que permitiu a detecção de melhorias e ainda de atividades secundárias que poderiam ser eliminadas deste processo por não agregarem valor ao serviço prestado pela logística. Outra vantagem foi a possibilidade de verificação se o número de páletes movimentados informado pelas unidades de negócio estava próximo do número real movimentado ao longo do ano. Destaque-se, ainda, que a logística da BASF passou a ter em mãos uma documentação que poderia ser apresentada às divisões (clientes) caso houvesse algum questionamento dos valores cobrados mensalmente.

Deve ser citado, também, que a determinação dos custos foi feita em função da complexidade das atividades realizadas e dos tempos para a realização das mesmas e não somente pelo número de páletes. Isso fez com que o novo método de custeio conseguisse apurar os custos de cada SBU de forma mais justa e, além disso, ajudasse a detectar qual atividade apresentava maior valor, facilitando a identificação de oportunidades de melhorias, como a seguir:

a) utilizando os direcionadores de custo será possível se ter um levantamento do histórico da demanda por SBU, que possibilitará a melhoria dos níveis de serviços prestados pela logística, de acordo com a variação na demanda de serviços ao longo do ano, levando-se em conta a sazonalidade da produção de cada produto; e

b) Possivelmente poderá ser feita uma reestruturação do quadro de funcionários (entenda-se realocação, desconsiderando-se a hipótese de demissões num primeiro momento).

Alguns cuidados foram tomados para que, de fato, o método $\mathrm{ABC}$ fosse um método justo de custeio, podendo ser realçado que foi de suma importância o lançamento correto das despesas nas contas de cada SBU.

Outro aspecto que deve ser objeto de reflexão é quando ocorreu a definição dos direcionadores de recursos e de atividades. Por exemplo, na determinação do direcionador de atividade estocagem chegou-se à conclusão que o direcionador ideal deveria ser o nível de estoque diário, mantido pelas SBU's nos depósitos da empresa, no entanto, não existia uma ferramenta na empresa que possibilitasse a identificação do saldo diário por SBU. A solução consensual foi calcular uma média dos valores de estoque diário em quatro datas ao longo de cada mês, e esse valor foi adotado como sendo o estoque diário. A empresa, preocupada com a acuracidade dos dados de entrada do método $\mathrm{ABC}$, já solicitou ao setor de informática uma ferramenta que possibilite a obtenção destes dados, já que eles se mostraram relevantes.

Entre as desvantagens observadas pode-se citar o tempo na obtenção das informações necessárias para o desenvolvimento do custeio mês a mês, sendo necessária a elaboração de vários relatórios no DW. De fato, foram necessários de sete a dez dias para a compilação dos dados para a aplicação no novo custeio. Pelo MTR a porcentagem de rateio era fixada a priori e não se alterava no tempo, assim os valores do rateio eram conhecidos com antecedência, já o novo método exige que sejam analisados vários dados para então se chegar na determinação das porcentagens mensais (mais justas) para cada SBU.

Com respeito aos principais serviços logísticos na BASF (Figura 2), a atividade fluxo de embalagens (Atividade 7) não foi incluída na aplicação do método $\mathrm{ABC}$ por se tratar de uma atividade recente na fábrica, necessitando de alguns ajustes no seu gerenciamento. Mas, pretende-se que logo ela esteja inserida nas atividades da logística e, a exemplo das demais atividades, ela também seja detalhada em atividades secundárias, como recebimento, estocagem, movimentação e expedição de embalagens para o uso do método ABC.

Finalmente, está sob consideração dos gestores da BASF a possibilidade de se trabalhar com um software específico para o método $\mathrm{ABC}$, inserido dentro do software ERP da SAP, para efeito de maior rapidez e agilidade na apuração dos dados necessários ao custeio. No entanto, deve ser feita uma ressalva em favor da estratégia adotada inicialmente, que foi a utilização de planilhas do Microsoft ${ }^{\circledR}$ Excel, para o convencimento das gerências das SBU para a implantação do método ABC, pois como o Excel é de amplo conhecimento e domínio, a aceitação do novo procedimento de custeio foi facilitada. 


\section{Conclusão}

Entre os objetivos estratégicos de uma empresa encontra-se a busca por vantagem competitiva, como um diferencial que a empresa pode adquirir, através da criação de valor para o cliente. Valor este, que geralmente é a utilidade percebida pelo cliente aos produtos que a empresa fornece. Dentro deste contexto apresentado, o sucesso passa a ser uma conseqüência da capacidade de produzir a baixos custos e ainda oferecendo produtos com maior diferença perceptível de valor. Assim, a gestão da cadeia logística deve buscar o desenvolvimento destas vantagens, ou seja, deve ser entendido o processo logístico assim como a busca da sua otimização que resultará da adoção de instrumentos que permitam o controle e colaborem para a identificação de oportunidades de melhorias contínuas destes processos.

$\mathrm{O}$ modelo de custeio aqui descrito vem ao encontro destes objetivos ao fornecer uma apuração justa do custeio de produtos e serviços. Para isso, o modelo partiu da identificação dos recursos utilizados e das atividades desenvolvidas no processo logístico analisado, chegando aos custos por unidades de negócios. Neste contexto, foram considerados como principais processos da logística as seguintes atividades que foram objetos de estudo para aplicação do modelo: recebimento, estocagem, movimentação interna de entrega, movimentação interna de retirada, expedição operacional, administração da expedição e fluxo de embalagens. No piloto da implantação, optou-se por trabalhar com um menor grau de detalhamento, para que o método não se tornasse dispendioso com a adoção de direcionadores de custos complexos e um alto grau de detalhamento na apuração dos custos. A finalidade básica do modelo não foi a obtenção de um custeio exato, e sim valores de custeio precisos, que minimizassem as distorções que os métodos tradicionais não conseguiam apurar, num contexto em que os custos indiretos se tornaram cada vez mais representativos.

Foi possível constatar que o método $\mathrm{ABC}$ contribuiu para: o gerenciamento dos custos logísticos, na medida em que forneceu informações quantitativas baseadas em atividades; melhor avaliação do fluxo de determinados processos; facilidade para a análise do fluxo de processos alternativos baseados em informações econômicas; determinação do custo relativo de várias atividades e o efeito potencial de mudanças; identificação de produtos, clientes e canais de distribuição rentáveis e melhor direcionamento no relacionamento entre empresa e fornecedores. Pode-se afirmar que o objetivo do trabalho foi atingido uma vez que o método $\mathrm{ABC}$ foi desenvolvido e implantado na BASF S.A., propiciando um novo e detalhado modelo de custeio da logística interna da empresa analisada. O trabalho demonstrou na prática sua viabilidade, apresentando baixo custo e agilidade e contemplando as principais atividades da logística interna por meio de um modelo simplificado de custeio. Além disso, os resultados forneceram subsídios para o processo de tomada de decisão e oportunidades de melhorias.

Para corroborar com tudo que foi exposto neste artigo, ao final da implantação do novo método de custeio foi feita uma pesquisa entre os gestores (tomadores de decisão) na empresa e os resultados podem ser resumidos a seguir, são eles:

a) houve unanimidade quanto a alguns aspectos positivos, como o fato do método $\mathrm{ABC}$ propiciar uma forma de cobrança justa, sendo feita em função do real uso das atividades e recursos no período;

b) o novo método evita discussões referentes ao sistema de cobrança, o que era muito freqüente anteriormente, o que gerava desgaste e desconfiança entre as várias áreas envolvidas, por fornecer material suficiente à logística para responder a questionamentos sobre a cobrança de seus serviços;

c) há clareza para todos os envolvidos sobre a forma de rateio;

d) observou-se que as distorções observadas na comparação dos resultados do novo modelo com as do modelo anteriormente utilizado pela empresa e utilizado até então estariam levando a decisões equivocadas por parte da gerência e prejudicariam a evolução da empresa;

e) o procedimento é simples, no entanto há a necessidade de que ele seja automatizado;

f) faz-se necessário discutir a aquisição de um software para determinação das porcentagens e que utilize os conceitos do método $\mathrm{ABC}$ na apropriação dos custos; e

g) todos acreditam que a nova forma de rateio é uma tendência para um futuro próximo em todas as áreas de negócio da empresa. 


\title{
Activity-based costing applied to the internal logistics of a chemical company
}

\begin{abstract}
This paper describes an Activity-Based Costin $(A B C)$ model implemented for the costing of the internal logistics of the chemical company BASF S.A. located in Guaratinguetá, state of São Paulo, Brazil. All the phases involved in the change from the traditional costing model to the $A B C$ model adopted by the company as presented, as are the difficulties, the solutions for detected problems, and the advantages gained. The Logistics Department of BASF acts as a service provider for all the productive processes of the company's departments (Sales Business Units - SBUs) in the Guaratingueta plant in terms of raw material storage and supply, and in the removal and storage of end products. The main results were improved costing of the SBUs, identification of opportunities for improvements in logistic processes, the detection of processes and activities that do not add value to products, etc. Lastly, the implementation process and the results were considered very positive by the managers, whose evaluation was decisive for the adoption of the $A B C$ model as the company's logistics cost management system.
\end{abstract}

Keywords: Activity-based costing. Costing. Internal logistics. Chemical company. Case study.

\section{Referências bibliográficas}

BALlOU, R. H. Gerenciamento da Cadeia de Suprimentos: Planejamento, organização e logística empresarial. 5. ed. Porto Alegre: Bookman, 2006.

BLOCHER, E. J.; CHEN, K. H.; COKINS, G.; LIN, T. W. Gestão Estratégica de Custos. 3 ${ }^{\text {a }}$ ed. São Paulo: McGraw - Hill, 2007.

BORGES, M. A. Método ABC (activity-based costing) aplicado ao Processo de Logística de Distribuição: o caso da indústria de computadores. Porto Alegre, 2003. Dissertação - (Mestrado em Engenharia de Produção), Universidade Federal do Rio Grande do Sul.

BORNIA, A. C. Análise Gerencial de Custos. São Paulo: Bookman, 2002.

COGAN, S. Activity- Based Costing (ABC): A poderosa estratégia empresarial. 3. ed. São Paulo: Pioneira Thomson Learning, 2000.

Cooper, R.; Kaplan, R. S. Measure costs right: Make the right decisions. Harvard Business Review, Harvard, Sept-Oct, p. 96-103, 1988

CREPALDI, S. A. Curso Básico de Contabilidade de Custos. São Paulo: Atlas, 1999.

FARIA, A. C.; COSTA, M. F. G. Gestão de Custos Logísticos. São Paulo: Atlas, 2005.

FREDERICO, G. F.; SOUZA, F. M.; CAVENAGHI, V.; SOUZA, L. F.; VOLPATO, P. R. O Sistema de custos MÉTODO ABC: um modelo de utilização para uma operação logística de transporte ferroviário. In: Simpósio de Engenharia de Produção - SIMPEP, 13, Bauru, SP. Anais... Bauru, 2006. (CD ROM).

GARRISON, R. H.; NOREEN, E. W. Contabilidade Gerencial. 9. ed. Rio de Janeiro: Livros Técnicos e Científicos (LTC), 2001

GIL, A. C. Métodos e Técnicas de Pesquisa Social. São Paulo: Atlas, 1994.
KAPLAN, R. S.; COOPER, R. Custo e Desempenho: administre seus custos para ser mais competitivo. 2. ed. São Paulo: Futura, 2000.

LA LONDE, B. J.; POLEN, T. L. Survey of activity-based costing applications within business logistics. In: Annual Conference of the Council of Logistics Management, 1998. Proceedings...

LEONE, G. S. G. Curso de Contabilidade de Custos. São Paulo: Atlas, 1997.

MAEHLER, A. E.; RODRIGUES, E. G.; CASSANEGO JUNIOR, P. Utilização dos métodos de custeio como ferramenta decisória em organizações hospitalares. In: Simpósio de Engenharia de Produção - SIMPEP, 12, 2006, Bauru, SP. Proceedings... Bauru, 2006. (CD ROM).

MARCONI, M. A.; LAKATOS, E. Técnicas de Pesquisa. 4. ed. São Paulo: Editora Atlas, 1999.

MARTINS, E. Contabilidade de Custos. 9. ed. São Paulo: Atlas, 2003.

NOVAES, A. G. Logística e Gerenciamento da Cadeia de Distribuição: estratégia, operação e avaliação. Rio de Janeiro: Campus, 2001.

PADOVEZE, C. L. Contabilidade Gerencial: Um enfoque em sistema de informação contábil. São Paulo: Atlas, 1997.

SABADIN, A. L.; FERNANDES, F. C.; FASSINA, P. H.; MOROZINI, J. F.; HOELTGEBAUM, M. Integração do Custeio Método ABC com o Método UP: uma evidência de suas relevâncias. In: Simpósio de Excelência em Gestão e Tecnologia - SEGeT, 3, 2006, Resende - RJ. Anais... Resende, RJ, 2006. (CD ROM).

SILVA, E. L.; MENESES, E. M. Metodologia da Pesquisa e Elaboração de Dissertação. 5. ed. Florianópolis: UFSC, 2005. 
Sobre os autores

\section{Themis Castro de Vasconcellos}

Departamento de Logística,

Avenida Brasil, 791, CEP 12521-140, Guaratinguetá, SP, Brasil,

e-mail: themis.vasconcelos@basf.com

\section{Fernando Augusto Silva Marins}

DPD-FEG-UNESP,

e-mail: fmarins@feg.unesp.br

\section{Jorge Muniz Junior}

Grupo de Otimização e Logística - GOL, Departamento de Produção, Faculdade de Engenharia, Campus de Guaratinguetá, Universidade Estadual Paulista, UNESP, Avenida Ariberto Pereira da Cunha, 333, 12516-410, Guaratinguetá, SP, Brasil, e-mai: jorgemuniz@ feg.unesp.br

Agradecimentos: Os autores agradecem à BASF S.A. e, de modo particular, ao Departamento de Logística. Fica, ainda, o agradecimento aos referees anônimos que contribuíram com valiosas sugestões para o aprimoramento do texto final.

Recebido em 13/3/2007 Aceito em 21/12/2007 